\title{
Numerical Investigation on Bearing Capacity of a Pipeline on Clayey Soils
}

Conference Paper · January 2010

DOI: 10.1115/OMAE2010-20200

CITATION

1

3 authors, including:

Fu-Ping Gao

Chinese Academy of Sciences

60 PUBLICATIONS 387 CITATIONS

SEE PROFILE
READS

11 


\title{
NUMERICAL INVESTIGATION ON BEARING CAPACITY OF A PIPELINE ON CLAYEY SOILS
}

\author{
Bo Zhao ${ }^{1,2}$, Fu-Ping Gao ${ }^{1 *}$, Rong-Yu Kang ${ }^{2}$ \\ ${ }^{1}$ Key Laboratory for Hydrodynamics and Ocean Engineering, Institute of Mechanics, Chinese Academy \\ of Sciences, Beijing, China \\ ${ }^{2}$ Design and Research Center, China National Petroleum Offshore Engineering CO.LTD., Beijing, \\ China
}

\section{ABSTRACT}

The bearing capacity of a pipeline foundation is crucial for the pipeline stability design. It is usually inappropriate to analyze the bearing capacity for the pipeline with special circular section directly by employing the theory for conventional rectangular strip footings. In this study, the ultimate loads of the pipeline on clayey soils are investigated numerically.

A plane-strain finite element model is proposed to simulate the quasi-static process of the pipeline penetrating into the soil, in which the adaptive-grid technique and the 'contactpair' algorithm are employed, and the Drucker-Prager constitutive model is used for modeling the soil plasticity. Based on the proposed numerical model, the development of soil plastic zone and the incremental-displacement vector field beneath the pipeline are examined numerically. It is indicated that, according to the obtained pipeline vertical loaddisplacement curves, concurrently referring to the plastic strain field and/or the soil incremental-displacement vector field, the shear failure type (e.g., general shear failure, punching shear failure) and the collapse loads can be thereby determined. The present numerical results match well with the analytical solutions of slip-line theory in plasticity mechanics.

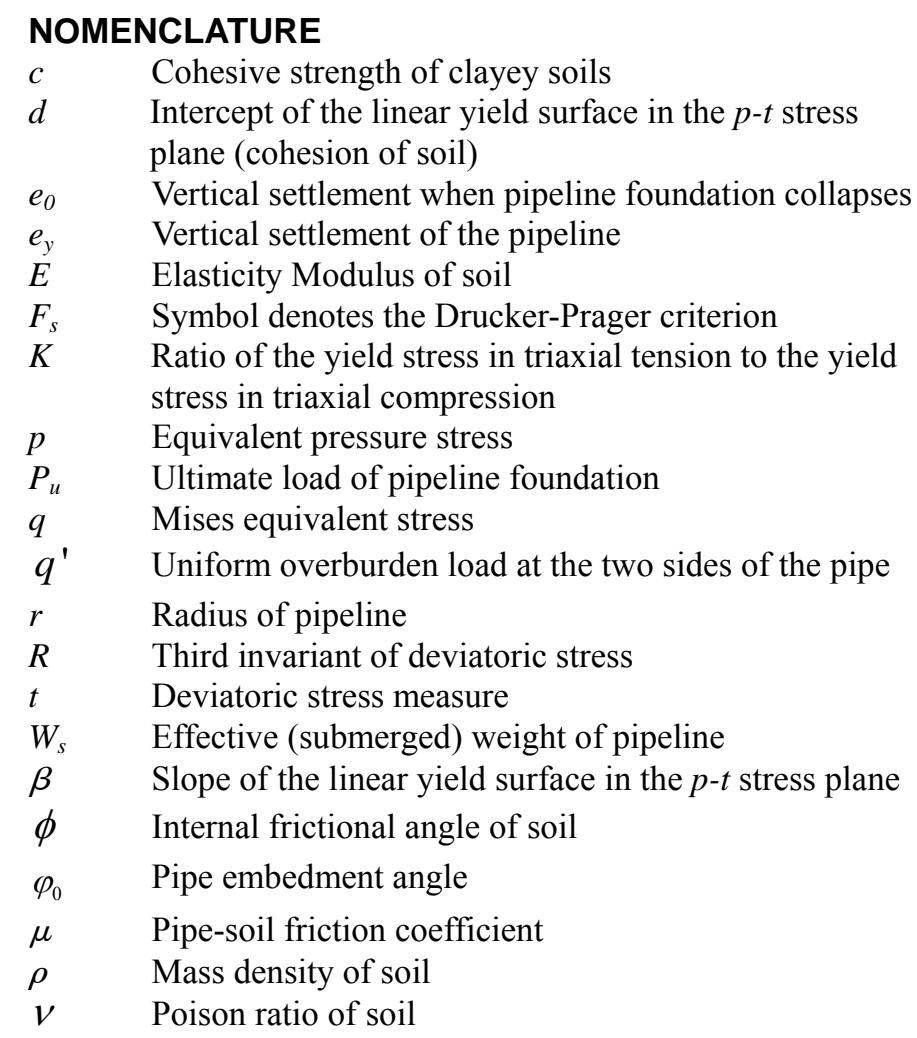

\footnotetext{
* Professor and Corresponding Author, fpgao@imech.ac.cn
} 


\section{INTRODUCTION}

Bearing capacity of the pipeline foundation is crucial for the pipeline vertical stability. In the recently issued DNV Recommended Practice "On-Bottom Stability Design of Submarine Pipelines" [1], the vertical stability of pipelines on and in soils has been specially defined, along with the lateral stability.

When laid on the seabed, the submarine pipeline settles into the soil under the action of its submerged weight. During the laying process or the operating period, additional vertical loads can also be created at the touchdown zones due to the catenary riser actions. The bearing capacity of (soft) clayey sediments is one of the main geotechnical concerns for the vertical stability of pipelines, especially in deepwater conditions.

The settlement and bearing capacity of the pipeline have received much attention in the past few decades. Conventional bearing capacity theories are mainly for the footings with plane bottom. In the theoretical analyses, the soil is absolutely divided into the plastic yield zone and the outer elastic deformation zone. Small et al. [2] treated the pipeline with certain submerged weight as an equivalent uniform distributed pressure upon a rectangular footing, and proposed empirical formulas for the bearing capacity factors by modifying the solutions for a conventional strip footing. Their treatment obviously could not take into account the effects of the circular section of the pipeline. Upper (unsafe) bound solutions for the vertical collapse load of a shallowly embedded pipeline were presented by Murff et al. for assessing the pipeline embedment into the undrained clay [3]. Aubeny et al. [4] further considered soil profiles with the shear strength varying linearly with depth. Zhao et al. [5] obtained the slip-line field solutions of the bearing capacity of the pipeline on Tresca soils. The theoretical analyses are usually valid for the soil suffering general shear failure.

Numerical method has also been employed to investigate the bearing capacity of footings, for its potential capability of simulating the development of elasto-plastic deformation beneath the footing at separate loading stages. The use of finite element analysis (FEA) in studying bearing capacity can be tracked back to 1982 when Griffiths et al. studied the bearing capacity factors of a strip footing [6]. Pastor et al. [7] studied the seabed characteristics during pipeline's vertical penetration for both homogeneous and inhomogeneous soils. Bransby et al. [8] modeled the soil heave around the pipe by using a largestrain finite element formulation, and concluded that the bearing capacity increases slightly with increasing the unit weight of soil, but the effect of surface heave on the bearing capacity is not significant.

This paper aims to numerically investigate the bearing capacity of the pipeline on clayey soils. A plan-strain FEA model for pipe penetrating into soils is proposed. The development of soil plastic zone and the incrementaldisplacement vector field beneath the pipeline are studied numerically. The failure mechanism of the pipeline foundation is examined. Moreover, the numerical results are compared with the previous slip-line theoretical solutions.

\section{FINITE ELEMENT MODEL}

\subsection{FEA Model for Pipe Penetrating into Soils}

The length of a submarine pipeline is usually much larger than its section dimension. When the pipeline is laid on the seabed, it settles into the soil under the action of its submerged weight. The bearing capacity of pipeline foundation can be treated as a plane-strain problem.

In the finite element analysis (FEA), it is reasonable for the pipeline to be regarded as a rigid cylinder for the reason that the stiffness of steel pipeline is much larger than that of soils. The examined clayey soil is modeled with the linear DruckerPrager (D-P) elastoplasticity constitutive model (see Section 2.2). As well-known, the clayey soil can be essentially assumed to behavior as an elastic Tessca material, and as an elastic $c$ $\phi$ material (e.g. Mohr-Coulomb or D-P material), if drained bearing capacity is under investigation.

The FEA mesh of the plane-strain model and the boundary conditions are illustrated in Fig. 1. For the plane symmetry of the problem, half of the full geometry needs to be considered with the following boundary conditions:

(1) Symmetry Boundary (left boundary): no displacement occurs in the $x$ direction, and no rotation is permitted;

(2) Right Boundary: no displacement in the $x$ direction;

(3) Bottom Boundary: a fixed boundary, i.e. the displacement and rotation are not permitted;

(4) Interface between Pipe and Seabed Surface: the contact-pair algorithm is adopted to simulate pipe-soil interaction. The left non-contact surface of the seabed is treated as a free boundary. The pipe-soil interface changes while the pipe penetrating into the soil. As such, it is crucial to deal with the contact surface between seabed and pipeline in the numerical modeling. The contact-pair algorithm provided in the ABAQUS software [10] is adopted, and the pipe-soil friction is defined by the Penalty Function with the advantage that it guarantees the positive definiteness of sparse matrix in the calculation. To avoid large distortion of FEM elements causing the calculation misconvergence, self-adaptive mesh technology is employed in the numerical modeling.

To obtain high calculation efficiency, the finite element mesh gets more refined at closer proximity to the pipe. Based on the results of a series of trial calculations [9], the width of numerical model is set as 20r and the depth as $20 r$ ( $r$ is the pipe radius). 


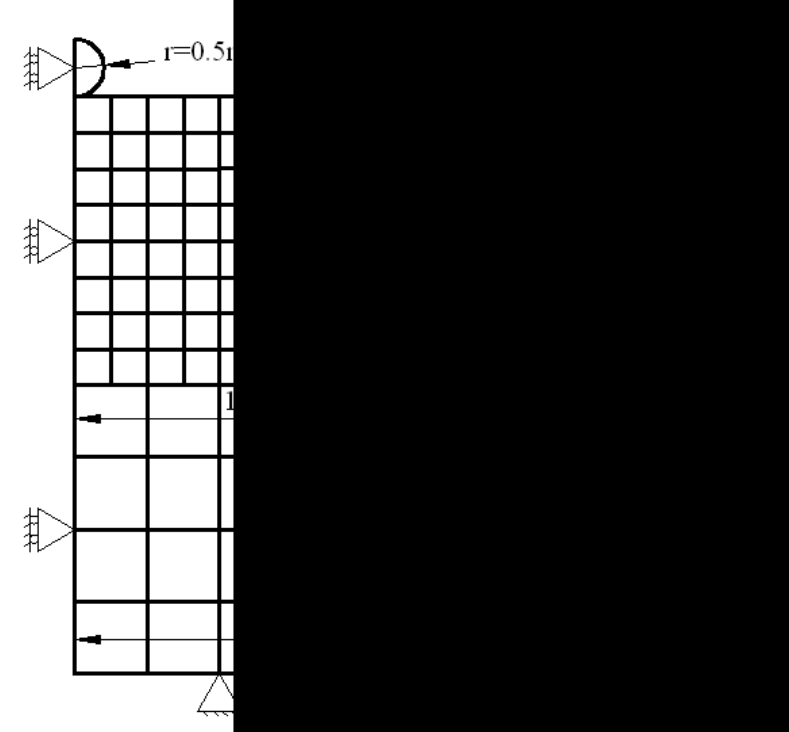

Fig.1 Illustration of the FEM mesh of plane-strain model and the boundary conditions

\subsection{Soil Constitutive Model and Parameters}

The linear Drucker-Prager model is chosen for its simplicity to simulate the elastoplastic behavior of the clay soils, which provides for a possibly noncircular yield surface in the deviatoric plane ( $\pi$-plane) to match different yield values in triaxial tension and compression, associated inelastic flow in the deviatoric plane, and separate dilation and friction angles. The linear Drucker-Prager criterion, i.e. the yield surfaces in the meridional $p$ - $t$ plane, is written as [10]:

$$
F_{s}=t-p \tan \beta-d=0
$$

where $t$ is the deviatoric stress measure, i.e.

$$
t=\frac{1}{2} q\left[1+\frac{1}{K}-\left(1-\frac{1}{K}\right)\left(\frac{R}{q}\right)^{3}\right]
$$

in which $p$ is the equivalent pressure stress; $K$ is the ratio of the yield stress in triaxial tension to the yield stress in triaxial compression and, thus, controls the dependence of the yield surface on the value of the intermediate principal stress (when $K=1.0, t=q$ implying that the yield surface is the von Mises circle in the deviatoric principal stress plane), $R$ is the third invariant of deviatoric stress, $q$ is the Mises equivalent stress; $\beta$ is the slope of the linear yield surface in the $p$ - $t$ stress plane and is commonly referred to as the friction angle of the material; and $d$ is the intercept of the linear yield surface in the $p$ - $t$ stress plane and is commonly referred to as the cohesion of the material.

The values of friction angle $(\phi)$ and cohesion $(c)$ for the Mohr-Coulomb model can be provided directly with the available tri-axial experimental data. For such a plane-strain problem and for the case of associated plastic flow, the values of the parameters in the linear Drucker-Prager model are related to the Mohr-Coulomb parameters by the following relationships [10]:

$$
\begin{aligned}
& \tan \beta=\frac{\sqrt{3} \sin \phi}{\sqrt{1+\frac{1}{3} \sin ^{2} \phi}} \\
& \frac{d}{c}=\frac{\sqrt{3} \cos \phi}{\sqrt{1+\frac{1}{3} \sin ^{2} \phi}}
\end{aligned}
$$

In the simulations, the parameters of soil are chosen as follows: elasticity modulus $E=1.0 \mathrm{MPa}$, mass density $\rho=1.58 \times 10^{3} \mathrm{~kg} / \mathrm{m}^{3}$, Poisson ratio $v=0.3$. Other soil parameters (e.g. $c, \phi$ ) are changed for the parametric study in Section 3. As aforementioned, the pipe is treated as a rigid cylinder with the radius $r=0.25 \mathrm{~m}$. The pipe-soil friction coefficients are varied $\mu=0 \sim 0.7$.

\section{NUMERICAL RESULTS AND ANALYSES}

The pipe settlements and soil plastic deformations under the action of the submerged weight of the pipe are simulated with the proposed numerical model. The curves for the vertical loaddisplacement relationships are plotted to estimate the failure type of pipe foundation and the corresponding bearing capacity. The development of plastic zone underlying the pipe under vertical loads is examined numerically. Furthermore, comparisons are made between the present numerical results and the slip-lines theoretical solutions.

\subsection{Failure Types of Pipe Foundation and Determination of Bearing Capacity}

For a conventional rectangular strip footing under vertical loading, there are usually three failure types, i.e. the general shear failure, the local shear failure and the punching shear failure. The failure type can be determined relatively easily with the load-displacement curve. Nevertheless, the situation may become more complicated for the pipeline foundations with circular section.

The curves for pipeline vertical load-displacement relationships and the soil plastic strain distributions at the critical value along the load-displacement curve are shown in Fig. 2(a)-(b), and Fig. 2(c)-(d), respectively, for two typical values of cohesion of clayey soils. Fig. 2(a)-(b) indicate that, those two vertical load-displacement curves are similar in profile with that of conventional strip footing suffering from a punching shear failure. Fig. 2(c) gives the distribution of soil equivalent plastic strain at critical value of $W_{s}$ for the clayey soils with $c=20.21 \mathrm{kPa}$, which shows that the plastic zone is located just beneath the pipe, i.e. no plastic deformation occurs besides the pipeline. This plastic deformation distribution indicates that the pipe foundation $(c=20.21 \mathrm{kPa})$ suffers a punching shear failure. The corresponding ultimate load (or 
named as "collapse load") $P_{u} \approx 38.0 \mathrm{kN} / \mathrm{m}$ (see Fig. 2(a)). Unlike the plastic deformation in Fig. 2(c), the plastic zone in Fig. 2(d) extends from beneath the pipe to the seabed surface besides the pipe, indicating the pipe foundation $(c=5.77 \mathrm{kPa})$ suffers a general shear failure (the ultimate load $P_{u} \approx 10.0 \mathrm{kN} / \mathrm{m}$, see Fig. 2(b)).

Therefore, it is usually difficult to determine the failure type of pipeline foundations only from the profile of vertical loaddisplacement curve, as their profiles are similar for different failure types due to the special circular sections of the pipe. When the turning point (from gentle to steep incline) along the load-displacement curve is not distinguishable, the plastic zone beneath the pipe foundation should be referred for determination of the ultimate loads.

The development of plastic zone beneath the pipe foundation and the corresponding incremental-displacement vector will be discussed in the following sub-sections.

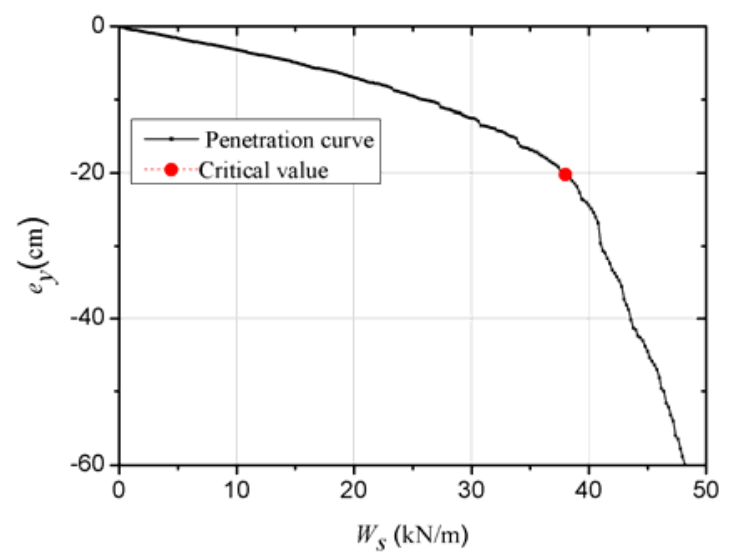

(a)

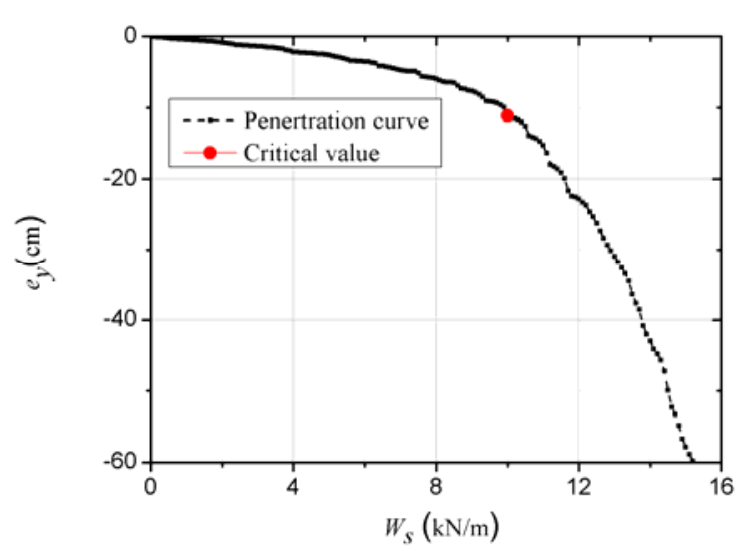

(b)

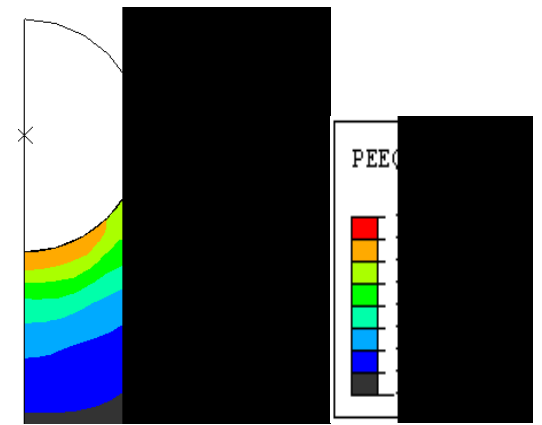

(c)

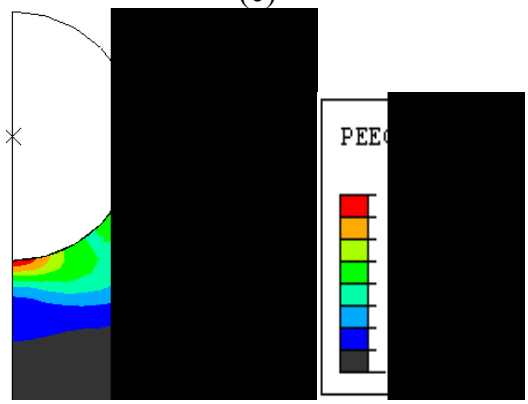

(d)

Fig.2 Vertical load-displacement curve and distribution of equivalent plastic zone for the pipe $(r=0.25 \mathrm{~m}, \mu=0)$ : (a) and

$$
\text { (c): } c=20.21 \mathrm{kPa} ;(\mathrm{b}) \text { and }(\mathrm{d}): \quad c=5.77 \mathrm{kPa}
$$

\subsection{Development of Soil Plastic Zone beneath the Pipeline}

The development of plastic zone beneath the pipe foundation with the increase of vertical loads is shown in Fig.3. The soil parameters $\phi=0, c=5.77 \mathrm{kPa}$ and the pipe-soil friction coefficient $\mu=0.7$. When the effective downward load on the pipe is small, the plastic zone is just located beneath the pipe (see Fig 3(a)). With the increase of the effective loads, the plastic zone extends gradually to the soil surface beside the pipe (see Fig 3(b)-(c)), indicating the pipeline foundation suffers a general shear failure. Compared with the smooth pipe (the ultimate load $P_{u} \approx 10.0 \mathrm{kN} / \mathrm{m}$, for $\mu=0$, see Fig. $2(\mathrm{~d})$ ), this rough pipe obtains a higher ultimate loads due to the increase of pipe-soil friction coefficient ( $P_{u} \approx 15.1 \mathrm{kN} / \mathrm{m}$, for $\mu=0.7$, see Fig. 3(c)).

Fig. 4 shows the development of the punching shear failure to the pipe foundation $(\phi=0, c=20.21 \mathrm{kPa})$. As shown in Fig 4(a)-(c), with increasing effective loads to pipe, the range of soil plastic zone becomes deeper beneath the pipe, i.e. in this case, no plastic deformation extending to the soil surfaces beside the pipe. For such a bigger value of soil cohesion, the punching shear failure of pipe foundation is more apt to be triggered. 


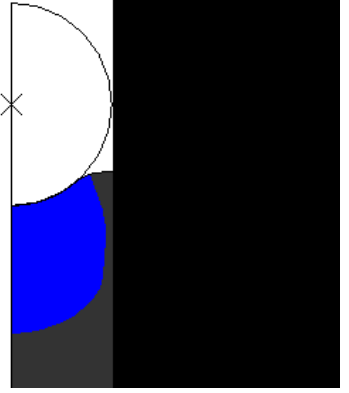

(a)

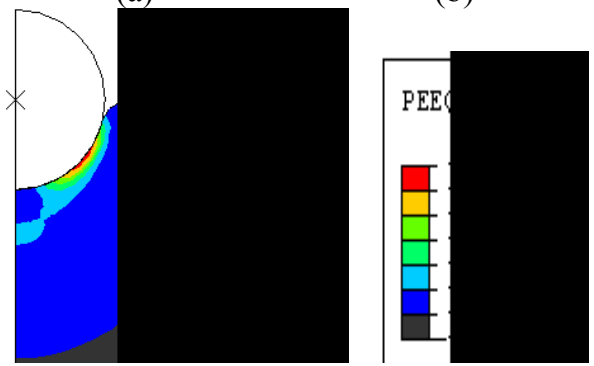

(c)

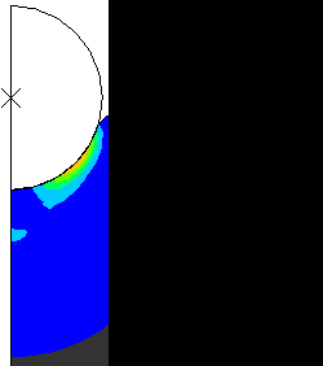

(b)
Fig.3 Development of plastic zone beneath the pipe foundation suffering a general shear failure $(c=5.77 \mathrm{kPa}, r=0.25 \mathrm{~m}$,

$$
\begin{gathered}
\mu=0.7 \text { ): (a) } W_{s}=10 \mathrm{kN} / \mathrm{m} ; \text { (b) } W_{s}=14.7 \mathrm{kN} / \mathrm{m} \text {; } \\
\text { (c) } W_{s}\left(=P_{u}\right)=15.1 \mathrm{kN} / \mathrm{m}
\end{gathered}
$$

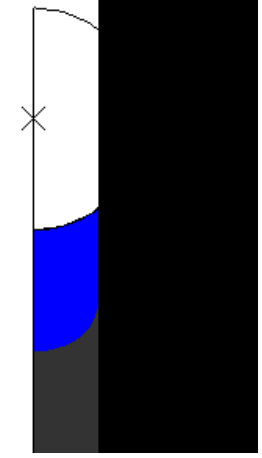

(a)

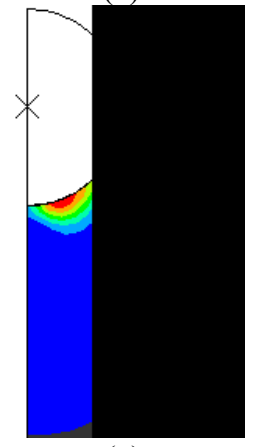

(c)

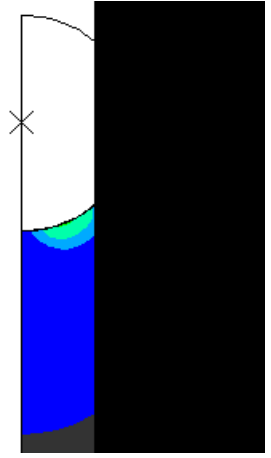

(b)

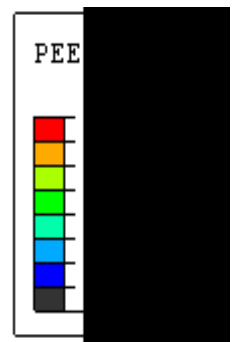

Fig.4 Development of plastic zone beneath the pipeline foundation suffering a punching shear failure $(c=20.21 \mathrm{kPa}, r$

$$
\begin{gathered}
=0.25 \mathrm{~m}, \mu=0.7 \text { ): (a) } W_{s}=27.2 \mathrm{kN} / \mathrm{m} ; \text { (b) } W_{s}=38.0 \mathrm{kN} / \mathrm{m} \text {; } \\
\text { (c) } W_{s}=45.0 \mathrm{kN} / \mathrm{m}
\end{gathered}
$$

\subsection{Incremental-displacement Vector Field beneath the Pipeline}

Fig. 5 shows the incremental-displacement vector fields at the ultimate load for the pipe foundation suffering a general shear failure for two values of pipe-soil friction coefficients. The orientation of the vectors indicates the direction of movement and their length the magnitude of movement. As it is the orientation of the vectors and their relative magnitude that indicates the failure mechanism, the absolute magnitude of the incremental displacements is irrelevant and no magnitude scale is given in the figures [11].

It is indicated in Fig. 5 that, the pipe-soil friction coefficient $(\mu)$ has some influence on the range of incrementaldisplacement vector field. The failure mechanism for the rough pipe is deeper and wider than that for the smooth pipe. For the rough pipe ( $\mu=0.5$ ), the soil just adjacent to the bottom of the pipe trends to move downward together with the settlement of the pipe. However, for the smooth pipe $(\mu=0)$, the adjacent soil is pressed by the moving pipe to spread aside, which induces the obvious upheaval of the soil surface in the proximity of the pipe. With the increase of $\mu$, the range of incremental-displacement vector field increases, which finally brings the increase of ultimate load to the pipe foundation.

Similar numerical results are also obtained for the pipe foundation with the increase of the internal friction angle from $\phi=0$ to $\phi=18^{0}$, as shown in Fig. 6. Comparison between Fig 5 and Fig 6 indicates that, the increase of internal friction angle of soil further enlarges the range of incrementaldisplacement vector field.

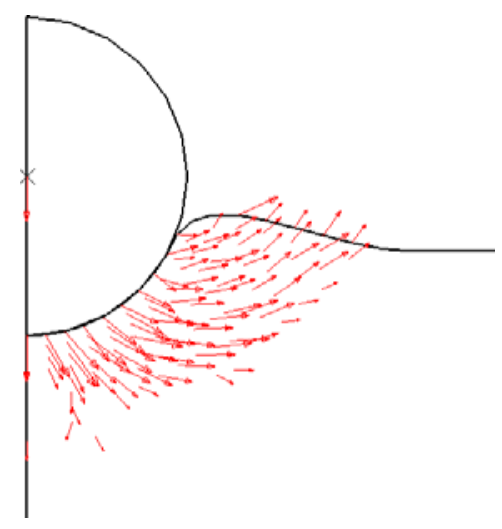

(a) 


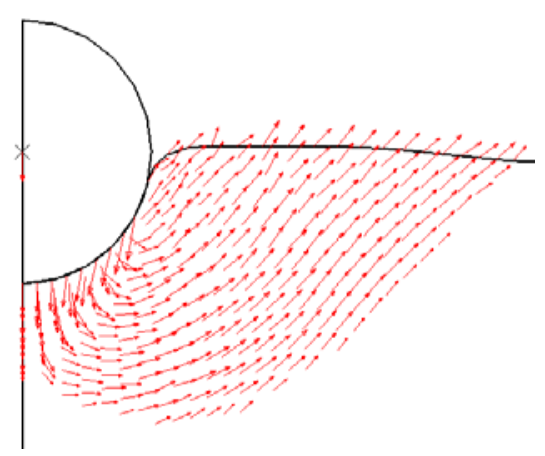

(b)

Fig.5 Incremental-displacement vector fields at ultimate load when the pipe foundation suffers a general shear failure for two values of pipe-soil friction coefficients $(c=5.77 \mathrm{kPa}$, $r=0.25 \mathrm{~m})$ : (a) $\mu=0$; (b) $\mu=0.5$

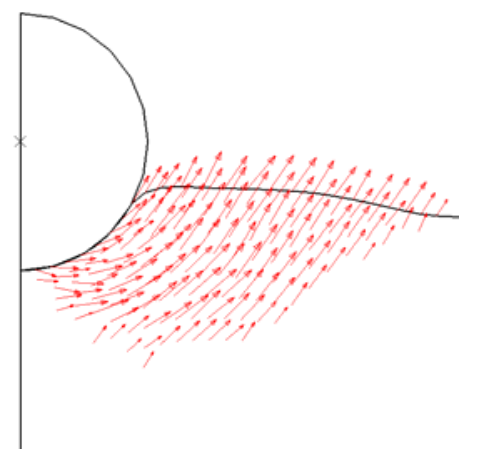

(a)

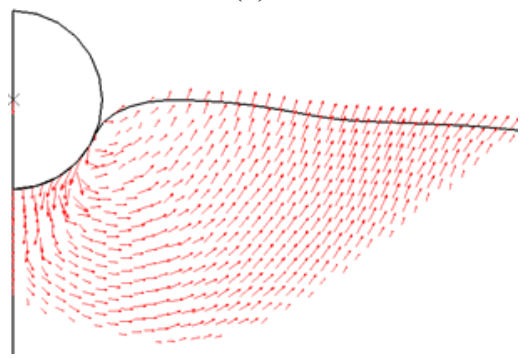

(b)

Fig.6 Incremental-displacement vector fields at ultimate load when the pipe foundation suffers a general shear failure for two values of pipe-soil friction coefficients $\left(\phi=18^{0}, c=5.0 \mathrm{kPa}\right)$ :

$$
\text { (a) } \mu=0 \text {; (b) } \mu=0.5
$$

\subsection{Comparison with Solutions of Slip-line Theory}

The slip-line field solutions for the ultimate load of submarine pipelines on a purely cohesive soil obeying Tresca yield criterion have been obtained by Zhao et al.[5], which are rewritten as follows:

$$
\frac{P_{u}}{2 r \sin \varphi_{0}}=c N_{c}+q^{\prime} N_{q}
$$

where $\varphi_{0}$ is the embedment angle (see Fig. 7): $\varphi_{0}=\arccos \left(1-e_{0} / r\right) ; q^{\prime}$ is the uniform overburden load at the two sides of the pipe $\left(q^{\prime}=0\right.$, when $\left.e_{0} / r \leq 1\right) ; N_{c}$ and $N_{q}$ are the bearing capacity factors:

$$
\begin{aligned}
N_{c}= & \frac{1}{\sin \varphi_{0}}(2+\pi+\Delta)\left[\sin \left(\varphi_{0}-\frac{\Delta}{2}\right)+\sin \left(\frac{\Delta}{2}\right)\right] \\
& -\frac{2}{\sin \varphi_{0}}\left[\varphi_{0} \sin \left(\varphi_{0}-\frac{\Delta}{2}\right)+\cos \left(\varphi_{0}-\frac{\Delta}{2}\right)-\cos \left(\frac{\Delta}{2}\right)\right] \\
N_{q}= & \frac{\sin \left(\varphi_{0}-\frac{\Delta}{2}\right)+\sin \left(\frac{\Delta}{2}\right)}{\sin \varphi_{0}}
\end{aligned}
$$

in which $\Delta=\arcsin \mu$.

According to the slip-line field theory, the coordinates of the slip-lines were obtained by solving the characteristic functions for slip-lines under boundary conditions using finitedifferential method [5], as shown in Fig. 7. The slip-line fields of theoretical solutions are quite comparable with the profiles of incremental-displacement vector fields at ultimate load when the pipe foundation suffers a general shear failure for two values of pipe-soil friction coefficients (see Fig. 5).

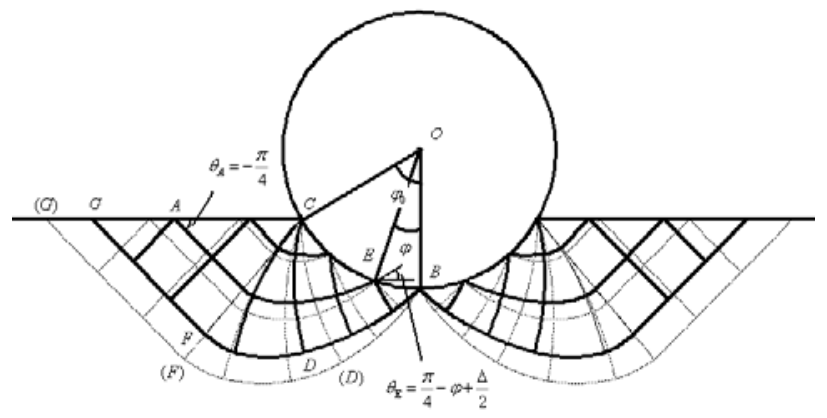

(b)

Fig. 7 Slip-line field of theoretical solutions $\left(e_{0} / r=0.5\right.$; solid line: $\mu=0$; dash line: $\mu=0.5$ ) by Zhao et al. [5]

To make a quantitative comparison with the above solutions of Slip-line theory, parametric studies are carried out. The parameters and the numerical results of the ultimate loads for pipe foundations are listed in Table 1. Note: in the Table 1, the symbol * presents the numerical results for pipe foundations suffering punching shear failure; the examined pipes are purely smooth $(\mu=0)$.

The aforementioned FEA method (see Section 3.1) is adopted for analysis on the determination of bearing capacity. That is, the failure type of pipeline foundations and the corresponding ultimate loads are determined by not only the profile of vertical load-displacement curve, but also by referring to the development of the plastic zone beneath the pipe, especially when the turning point from gentle to steep- 
incline along the load-displacement curve is not distinguishable.

Table 1. Numerical results of bearing capacity for pipe foundations.

\begin{tabular}{ccccc}
\hline $\begin{array}{c}e_{0} \\
(\mathrm{~m})\end{array}$ & $e_{0} / r$ & $\begin{array}{c}c \\
(\mathrm{kPa})\end{array}$ & $\begin{array}{c}P_{u} \\
(\mathrm{kN} / \mathrm{m})\end{array}$ & $P_{u} / c r$ \\
\hline 0.08 & 0.336 & 1.15 & 2.0 & 6.93 \\
\hline 0.11 & 0.444 & 5.77 & 10.0 & 6.93 \\
\hline 0.15 & 0.596 & 10.39 & 19.3 & 7.43 \\
0.19 & 0.784 & 15.01 & 29.5 & 7.86 \\
-0.20 & 0.808 & 20.20 & $38.0 *$ & NA \\
\hdashline 0.23 & 0.920 & 28.86 & $55.0 *$ & NA \\
\hline
\end{tabular}

Fig. 8 gives the comparison between the present FEA results with the solutions of slip-line filed theory for smooth pipes $(\mu=0)$, indicating their results match well with same trends of the variation of $P_{u} / c r$ with $e_{0} / r$, i.e. the dimensionless ultimate loads $\left(P_{u} / c r\right)$ increase gradually with the increase of the dimensionless pipe embedment $\left(e_{0} / r\right)$.

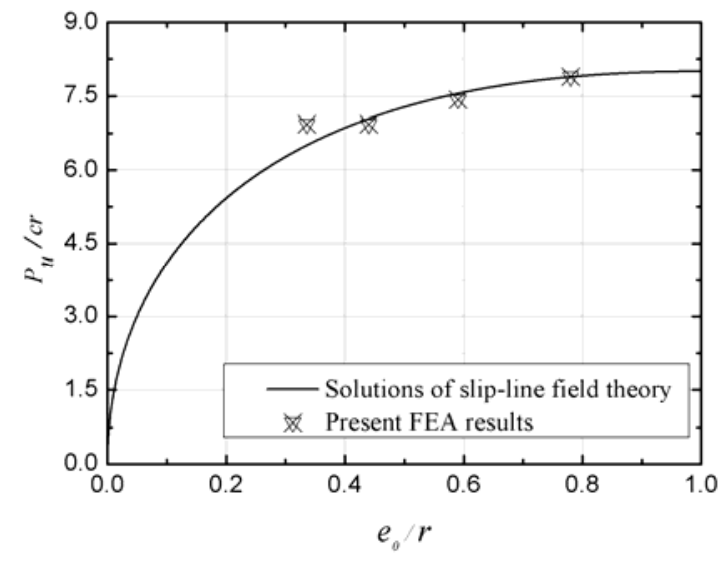

Fig. 8 Variation of $P_{u} / c r$ with $e_{0} / r$ : Comparison between present FEA results with the solutions of slip-line filed theory.

\section{CONCLUDING REMARKS}

The bearing capacity of a pipeline foundation is crucial for the pipeline stability design. In this paper, a plane-strain finite element model is proposed for analysis of the bearing capacity of pipeline on clayey soils. To simulate the quasi-static process of the pipeline penetrating into the soil, the adaptive grid technique and the 'contact pair' arithmetic are employed, and the Drucker-Prager constitutive model is used for modeling the soil plasticity.

The development of soil plastic zone and the incrementaldisplacement vector field beneath the pipeline are examined numerically for some values of soil cohesions and pipe-soil friction coefficients. It is indicated that, according to the obtained pipeline vertical load-displacement curves, concurrently referring to the plastic strain field and/or the soil incremental-displacement vector field, the shear failure type (e.g., general shear failure, punching shear failure) and the collapse loads can be thereby determined. The present numerical results match well with the analytical solutions of slip-line theory in plasticity mechanics.

\section{ACKNOWLEDGMENTS}

This work is financially supported by China National S\&T Major Project (No.2008ZX05026-005) and Knowledge Innovation Program of the Chinese Academy of Sciences (No. KJCX2-YW-L02).

\section{REFERENCE}

[1] Det Norske Veritas (2007). On-Bottom Stability Design of Submarine Pipelines. Recommended Practice, DNV-RPF109

[2] Small S W, Tambuvello R D, Piaseckyj P J (1971). "Submarine pipeline support by marine sediment," Offshore Technology Conference, OTC 1357:309-318.

[3] Murff J D, Wagner D A, Randolph M F (1989). "Pipe penetration in cohesive soil," Geotechnique, 39(2):213229.

[4] Aubeny C P, Shi H, Murff J D (2005). "Collapse loads for a cylinder embedded in trench in cohesive soil," Geotechnique, 5(4):320-325.

[5] Zhao B, Gao F P, Liu JM, Wu YX (2009). "Vertical Bearing Capacity of a Partially-Embedded Pipeline on Tresca Soils," Proceedings of the 19th (2009) International Offshore and Polar Engineering Conference, Osaka, 469-473.

[6] Griffiths DV (1982). "Computation of bearing capacity factors using finite elements," Geotechnique, 3:195-202.

[7] Pastor J, Turgeman S, Avallet C (1990). "Predicting the phenomenon of burying through gravity in purely cohesive sedimentary sea beds," Geotechnique, 39(4):625-639.

[8] Bransby M, Zajac P, Amman S (2008). "Finite element analysis of the vertical penetration of 'on-bottom' pipelines in clay," Proceedings of the 18th (2008) International Offshore and Polar Engineering Conference, 245-249

[9] Zhao B, Gao F P, Luo C C (2008). "Soil plasticity and shear failure properties of pipe foundation," Ship \& Ocean Engineering, 37(2): 95-99

[10] Hibbitt, Karlsson and Sorenson Inc. (2006). ABAQUS Theory Manual, Version 6.5-1.

[11] Potts DM and Zdravkovic L (2001). Finite Element Analysis in Geotechnical Engineering: Application. London: Thomas Telford Ltd. 